\title{
De merken van het lepers Edelsmedengilde
}

\section{Het Stadsmerk.}

Het oudste stadsmerk is het dubbel kruis uit het stadswapen van Ieper. Dit wapen werd reeds gebruikt als zegel in 1199 en verder gedurende de $13^{\circ}$ en $14^{\circ}$ eeuw ${ }^{1}$. Dit merk staat afgedrukt op de eerste koperplaat met de meestertekens, die uit 1525 dagtekent $^{2}$ (zie afb. 1 en 2).

Op 20 oktober 1608 verscheen een « Edikt en ordonnantie » van de Aartshertogen voor de goud- en zilversmeden, dat op 14 april 1612 met 14 artikelen werd aangevuld ${ }^{3}$.

Volgens Art. VII van die aanvulling moest men, naast het gewoon stadsmerk, dat men tot dan toe gebruikte, een tweede slaan, verschillend van het eerste ${ }^{4}$.

Het zilversmedengilde van Brugge nam als tweede merk een kleine gotische $b$ met kroon en dit wanneer als dekenletter een kleine gotische d gebruikt werd (van 2 september 1611 tot 2 september 1612) en Cornelis Blommaert deken was van het zilversmedengilde ${ }^{5}$.

In het Gentse gilde moet het ook in 1612 geweest zijn. Voor het eerst komt als tweede stadsmerk een gekroonde $\mathrm{G}$ voor, wanneer de dekenletter $\mathrm{K}$ gebruikt werd en dheer Franchois Vander Cruysen « heuverste » was.

1. de Ghellynck Vaernewijck, Sceaux et armoiries des Villes... de la Flandres, Parijs, Desclee De Brouwer, 1935, p. 386 en vlg.

2. Platen in het Jubelpark te Brussel. Afb. in Tablettes des Flandres, t. V (Brugge, 1953), p. 96, 104, 112, 120, en in de Cataloog: Tentoonstelling van Iepers en Rijsels edelsmeedwerk, Juni 1958.

3. Edikt gedrukt bij Rutgeert Velpius te Brussel 1608, en Ampliatie bij Jan Van den Steene te Gent 1612. Placcaert-boecken van Vlaenderen, t. II, fo $445-456$ en $456-460$.

4. Ampliatie van 1612 , art. VII.

5. Zie : Biekorf, 1950, blz. 249. 
Bij deze merken staat geen jaartal genoteerd, maar bij de dekenletter $M$ staat het jaartal 1614 en bij $P$ het jaartal 1617. Dan moet L gebruikt geweest zijn in 1613 en $\mathrm{K}$ in $1612^{6}$.

Het is dus het tweede gilde, dat aanstonds in 1612 het tweede stadsmerk gebruikte.

Wanneer de andere gilden hun tweede stadsmerk gebruikten, daarover zijn we niet zo goed ingelicht. De grote reden is dat er geen kunstgewrochten bewaard of bekend zijn van 1611-12.

Het vroegst bekende edelsmeedwerk van Doornik, waarop als tweede stadsmerk een gekroonde $\mathrm{T}$ voorkomt, is een kelk uit de St Brixiuskerk van Doornik van 1614-15.

Voor Ieper is het oudst bekende werk een ciborie uit de St. Niklaaskerk van Ieper uit het jaar 1623. Daarop komt als tweede stadsmerk de $\mathrm{Y}$ voor. Maar we mogen veronderstellen dat Ieper ook reeds in 1612-13 als tweede stadsmerk de gekroonde $\mathrm{Y}$ gebruikt heeft.

Op de eerste plaat van de Ieperse meestermerken staan links van het jaartal $\mathrm{XV}^{\circ}$ XXV (1525) de nieuwe stadsmerken (afb. 1).

Het gekroond dubbel kruis en de gekroonde $Y$ zijn dezelfde niet als die welke voorkomen op de ciborie van de St. Niklaaskerk (1623).

Kanunnik Crooij geeft als stadsmerk nr. 4 dit uit 1625 terwijl hij als nr. 5 dit van de eerste plaat overneemt. Dit laatste zal wel het tweede stadsmerk geweest zijn dat onmiddellijk gebruikt werd na het edikt van $1612^{7}$ (zie afb. 3).

Omstreeks 1664 werden de twee stadsmerken op de achterzijde van de derde plaat geslagen. Boven het dubbel kruis in een schild staan drie puntjes naast elkaar en boven de $\mathrm{Y}$ een kroon met drie puntjes in het midden, twee onder

6. J. Casier, Les orfèvres flamands et leurs poinçons, Gent, 1914, PI. IX $v^{\circ}$. In de inhoudstafel werd het jaar ingevuld tussen haakjes (1612).

7. L. \& F. Crooy, L'orfèvrerie religieuse en Belgique, Brussel, 1911, p. 106, fig, 4 \& 5 . 
en één er bovenop ( $\mathrm{afb}$. 4). Rond 1684-85 staan weerom de beide stadsmerken, maar het been van de $\mathrm{Y}$ staat omgekeerd, doch boven beide staan drie puntjes naast elkaar (afb. 5). Tussen de gotische dekenletter $\mathrm{C}$, die er tweemaal geslagen is, staan tweemaal de stadsmerken en beide zijn verschillend (afb. 6).

Door het verdrag van Nijmegem (17 september 1678) werd Ieper en zijn kasselrij frans gebied. Het gilde behield zijn eigen stadsmerken, niettegenstaande het min of meer afhankelijk was van Rijsel.

Veurne, die reeds in 1668 onder frans bewind stond, was vroeger afhankelijk van het Brugse gilde. Het kon nog niet met zekerheid worden uitgemaakt of het afhankelijk was van Ieper of Duinkerke. Dit laatste gilde gebruikte wel zijn eigen stadsmerk, maar was toch afhankelijk van Rijsel.

Een nieuwe verordening van Karel II, zoon van Filips IV, duidde in art. 14 het aantal goud- en zilversmeden aan, die er in ieder stad mochten zijn. In Brugge was dit : 20, in Diksmuide, Oostende en Nieuwpoort: elk $2^{8}$. Ieper en Veurne worden er niet in vernoemd, omdat ze onder frans bewind stonden.

$\mathrm{Na}$ het Verdrag van Rijswijk (20 sep. 1697) en het grensverdrag van Rijsel ( 3 dec. 1699) kreeg het Iepers gilde een nieuw stadsmerk nl. het gekroond dubbel kruis tussen $Y$ en $P$ ( $a f b .7$ ). Dit werd gebruikt tot 1713 , jaar waarin Ieper door het verdrag van Utrecht (11 april) onder Oostenrijks bewind kwam te staan.

Vanaf 1714 werd weerom het dubbel kruis en het tweede stadsmerk Y afzonderlijk geslagen, maar vanaf 1716 tot 1744 werd het been van de Y gedraaid (afb. 8).

Van 1744 tot 1748 werd de stad weerom door de fransen ingenomen. In deze jaren werd weerom het stadsmerk uit de periode 1699-1713 gebruikt. Dit kon opgemaakt worden omdat twee kunstwerken uit die periode gevonden werden en de dekenletters dezelfde niet zijn als in 1699 en 1700 .

8. Placcaert-boecken van Vlaenderen, t. IV, fo 1272 en volgende. 
Het meesterteken, dat er bij geslagen is, is dit van Jan-Baptist De Somer, die maar meester geworden is in 1710 ( $\mathrm{afb}$. 9 van Stadsmerk - dekenletter en meesterteken).

In een verordening van 19 september 1749 , door keizerin Maria Theresia uitgevaardigd, zegt art. XXI dat ieder meester goud- en zilversmid zich moet voorzien van een nieuw «poincoen ofte teecken ${ }^{9}$.

Vanaf 1750 heeft het Iepers gilde een nieuw tweede stadsmerk gebruikt. Het dubbel kruis werd behouden, maar $Y$ werd vervangen door een leeuwtje op zijn geheel (afb. 11). Deze beide stadsmerken werden gebruikt tot 1794 , toen onze gewesten onder frans bewind kwamen.

De fransen, die in 1791 eerst in eigen land, en daarna in de bezette gebieden, de gilden en de merken hadden afgeschaft, brachten de merken weerom in bij wet van 19 brumaire jaar VI ( 9 nov. 1797).

Vanaf 1797 tot 1808 gebruikte men voor de departementen een aanziende gebaarde mannenbust (vue de face) in een ovale omlijsting. De cijfers, die links en rechts van het hoofd stonden, duidden de stad aan. Voor Ieper wat het 54 met sterretje; voor Brugge 54 (afb. 12).

Van 1809 tot 1814 was het de kop van een oude man met baard, naar links gericht in een ronde omlijsting of een gehelmde mannenkop naar rechts gedraaid, volgens het gehalte zilver. In het eerste merk stond het getal links en rechts in de ronde omlijsting, in het tweede samen boven in de helm. Voor Ieper werd 56 gebruikt en voor Brugge 56*10 (afb. 13).

Toen ons land onder Hollands bewind kwam, werden geen stadsmerken meer gebruikt. Bij koninklijk besluit van 14 sept. 1814 werd voor de Zuidelijke Provincies als waarborgteken voor het zilver een gesloten hand, die een staafje omvat, voorgeschreven. Dit in een rond schild. Bo-

9. Placcaert-boecken van Vlaenderen, t. V, 2e Deel, $\mathrm{f}^{\circ}$ 270-286.

10. Een afbeelding van die nieuwe franse keurmerken in 1809 gebruikt, vindt men in: $19^{\circ}$ Eeuws zilver, Phoenix pockets, N 103, afb. 14. 
ven de duim van de gesloten hand staat A d.i. « argent ». Was het zilver van eerste gehalte dan gebruikte men als tweede merk het cijfer 1 in een kroon. Dit merk had een rechthoekige omlijsting met bolle hoeken. Voor zilver van tweede gehalte was het het cijfer 2 tussen twee gekruiste palmtakken in een vierkante omlijsting ${ }^{10 b i s}$.

\section{De Dekanaatsletters.}

Bij de vernieuwing van de eed of het bestuur van het gilde, d.i. wanneer een nieuwe deken met de vinders en warandeerders werd verkozen, werd een letter van het alfabet geslagen.

Die letter is de dekanaatsletter en kwam overeen met het jaar, waarin het ambt van de deken uitgeoefend werd.

De eed van het Brugse Zilversmedengilde werd vanaf 1363 tot 1374 regelmatig op 2 februari vernieuwd ${ }^{11}$. Vanaf 1398 tot 1627 (enkele onregelmatigheden uitgezonderd) gebeurde dit op 2 september. Vanaf 1627 tot 1750 was het heel wisselvallig ${ }^{11}$.

Voor die eerste periode werd dus een letter van het alfabet gebruikt b.v. vanaf 2 febr. 1363 tot 2 febr. 1364 , terwijl voor het tweede tijdstip b.v. van 2 sep. 1398 tot 12 sept. 1399. Gewoonlijk werden maar 24 letters gebruikt, daar $\mathrm{J}$ en $\mathrm{U}$ niet in aanmerking kwamen.

Voor de dekanaatsletters van het Ieperse Zilversmedengilde hebben we geen houvast, bij gebrek aan archivalische bronnen, daar het Iepers Stadsarchief onder de eerste Wereldoorlog vernield werd en bij gebrek aan edelsmeedwerk vóór 1623 , waarop een opschrift voorkomt. Vóór dit laatste tijdstip kan zelf niet met zekerheid de datum van de dekanaatsletter bepaald worden.

Op de voorzijde van de eerste plaat met de Ieperse meestertekens, staan bovenaan, naast het oudste stadsmerk volgende gotische hoofdletters A, B, C, E, H, I inrechthoekige

10bis. E. Voet Jr., Nederlandse goud-en zilvermerken 1445-(95), $2^{\mathrm{e}}$ druk ('s-Gravenhage, 1951), P1. III tegenover blz. 63.

11. Stadsarchief Brugge, registers van de wetsvernieuwingen over $1363-1374 ; 1378-1627 ; 1627-1750$. 
omlijsting (afb. 14). Boven op de plaat staat het jaartal $\mathrm{XV}^{\mathrm{c}} \mathrm{XXV}(1525)$ in gothische romeinse cijfers.

Indien we veronderstellen dat als dekanaatsletter in 1525 de gotische $A$ gebruikt werd en ieder jaar een ander letter geslagen werd, dan zou de gotische $Z$, die op de monstrans van de St.-Bavokerk te Watou voorkomt, ongetwijfeld tot dit eerste alfabet behoren en zou men 1548 kunnen vooropstellen. Het gaat echter niet op wat de gebroeders Crooy voorstelden, n.l. de eerste 9 letters ieder over een tijd van één jaar te laten lopen en de overige over twee jaar ${ }^{12}$. $\mathrm{Ze}$ meenden echter dat op die platen enkel de namen van de dekens voorkwamen. Dit zal verder bij de meestertekens op punt gesteld worden. Een ander bewijs wordt verder ook geleverd bij enkele families van zilversmeden vooral door Van der Meersch.

Op die eerste plaat staan nog vijf andere dekanaatsletters n.1. A B C N en $\mathrm{K}$ in gewone drukletters. Waarschijnlijk behoren ze zelf niet tot hetzelfde alfabet. De omlijsting is helemaal anders bij de eerste drie dan bij de laatste twee (afb. 13).

Tot welk alfabet ze behoorden en welk jaartal ermede overeenstemt kon niet worden uitgemaakt.

Een onvolledig alfabet kon worden opgemaakt, met behulp van werken voorzien van een opschrift. De hoofdletters komen telkens in een ronde omlijsting voor. Voor 1623 - 24 zou I gebruikt zijn geweest. Voor $1624-25: \mathrm{K}$, voor $1625-26: \mathrm{L}$, voor $1626-27: \mathrm{M}$, voor $1627-28: \mathrm{N}$, voor 1628 - 29: $\mathrm{O}$, voor $1629-30: \mathrm{P}$, voor $1630-33$ : $Q$, voor 1633 - $34: R$, voor 1634 - 35 : $S$.

Wanneer dit alfabet begon en eindigde is onmogelijk uit te maken. Een nieuw alfabet is begonnen rond 1664. Daarvan is alleen de drukletter A zonder kroon geslagen op de 4 e plaat (afb. 4 ).

Op de voorzijde van de $4 \mathrm{e}$ plaat komt een onvolledig alfabet voor in gothische minuskels. Na het merk van Pieter

12. L. \& F. Crooy, a.w., blz. 109-111. 
Van de Walle 1684 komt de gothische $\mathrm{b}$ en na dit van Anthone Billiau 1687 de gothische $\mathrm{C}$ daarna de volgende letters tot $\mathrm{O}$ ( $\mathrm{afb}, 6$ ). Dit alfabet zou begonnen zijn in 1683 en lopen tot 1698 , wanneer het onderbroken werd.

Of het alfabet vóór 1683 ten einde gelopen heeft, kan weerom niet worden uitgemaakt, omdat er geen edelsmeedwerk voorhanden is uit de periode 1635-1683.

Dat het alfabet in 1698 afgebroken werd en er dan een nieuw begon, zou dit niet geweest zijn ten gevolge van de politieke gebeurtenissen ? Ieper en de Kasselrij waren sedert het verdrag van Nijmegem (10-8-1678) aan Frankrijk gekomen. Roeselare afhankelijk van Ieper, kwam ten gevolge van het verdrag van Rijswijk met het grensverdrag van Rijsel nu ook aan Frankrijk. In 1699 begint dan een nieuw alfabet met nieuw stadsmerk, nl. het dubbel kruis tussen $\mathrm{Y}$ en $\mathrm{P}$ (zie hoger).

De eerste vier dekanaatsletters zijn geschreven $A, B, C, D$, terwijl van af $E$ tot $I$ het drukletters zijn met grote kroon, waarin de gestyliseerde lelie voorkomt (afb. 7). Dit alfabet loopt tot 1713 en wordt met K onderbroken. De laatste drie dekanaatsletters lopen van 1706 tot 1713 (afb. 7).

Door het verdrag van Utrecht (11-4-1713) kwam Ieper onder de Oostenrijkse Nederlanden.

In 1714 begint een nieuw alfabet, waarvan de letters niet altijd over één jaar lopen (plaat VII). Zo werd C gebruikt van 1716 tot $1719, \mathrm{E}$ van 1720 tot $1722, \mathrm{~F}$ van 1722 tot 1724 en L van 1728 tot 1730 . Dit alfabet liep ten einde in 1742. Het volgende begon in 1743. Daarvan staan maar twee letters op de plaat nl. A en B voor 1743 en 1744 .

Van 1744 tot 1749 stond Ieper opnieuw onder frans bewind. Een nieuw alfabet werd begonnen A met grote kroon, in 1745 . Hoeveel letters er gebruikt werden is niet bekend. Twee ervan werden op edelsmeedwerk aangetroffen nl. A en B met grote kroon ( $\mathrm{afb} .9$ ).

$\mathrm{Na}$ de verordening van 19 september 1749 door Maria Theresia uitgevaardigd, gebruikte het zilversmedengilde van 
Ieper geen dekanaatsletters meer, maar vanaf 1750 de laatste twee cijfers van het jaartal. Dat van 50 tot 94 (afb. 10).

\section{Het Meesterteken.}

Er zijn zes platen bewaard met meestertekens van Ieperse zilversmeden in het Jubelpark te Brussel ${ }^{13}$.

Het aantal zilversmeden, in het Iepers gild toegelaten, is niet juist bekend. Heel waarschijnlijk is dit 12 geweest.

De eerste plaat begint in 1525 en loopt tot ongeveer 1562 . Op de voorzijde staan de merken van 11 meesters, en op de achterzijde 11 merken; één is geschrapt. Op de achterzijde staat Jan de Guisy een tweede maal, maar met een ander merk. Als zesde op dezelfde plaat staat Herman Van Volden. In 1551 was hij warandeerder in het Brugse zilversmedengilde en is in dit jaar vertrokken ${ }^{14}$. Er zijn 4 verschillende merken van Roeland de Kien, doch of het dezelfde zilversmid was kan niet uitgemaakt worden.

De tweede plaat begint rond het jaar 1543. Deze datum staat achter het merk van Claeus. Op de voorzijde zijn 12 meestermerken geslagen en op de achterzijde ook 12, waarvan het laatste uit 1621 . De voorzijde draagt weerom een merk van een Brugse zilversmid, die het gilde verlaten had, nl. Joos Random ${ }^{15}$.

De derde plaat, die in 1629 begint, eindigt in 1683 . Op de voorzijde staan twee merken van 1629 , vijf zonder datum, twee van 1634 en twee uit 1639.

Het vierde meesterteken is dit van Adriaen Marisael, die tussen 1641 en 1648 naar het gilde van Gent overging. Op de derde plaat recto van Gent komt hetzelfde merk voor

13. Afgedrukt in Tablettes des Flandres, t. V, blz. 96, 3e Pl., blz. 104, 4e P1., blz. 112, 5e Pl. en blz. 120, 6e Pl. r'. In de Kataloog van de Tentoonstelling van Iepers en Rijsels Edelsmeedwerk. Ieper 22 Juni - 15 Juli 1958, werden al de platen afgedrukt blz. 54-60.

14. Stadsarchief, register van de wetsvernieuwingen over de jaren 1535-1571: 2 sept. 1551, f 125 : «Warandeerder: Herman Van Volden - ende midts 't vertrekken van desen Herman zo es in zijne stede ghestelt Bernaert vander Tolle».

15. Stadsarchief, register van de wetsvernieuwingen over de jaren 1535-1571 : sept. $1547, \mathrm{f}^{\circ} 93 \mathrm{v}^{\circ} ; 1544, \mathrm{f}^{\circ} 72$. 
als te: Ieper ${ }^{16}$. Op de achterkant staat een meesterteken van 1652 , één van 1655 , één van 1661 , twee van 1663 , drie van 1683 en twee zonder datum. Tussen het vijfde en zesde merk staan de twee stadsmerken en de dekanaatsletter A (afb. 4). Het derde laatste merk werd geschrapt. Het is dit van Jacques De Clerck. Hij was vroeger te Brugge gevestigd en was naar Ieper gegaan in 1683 , waar hij niet aanvaard werd ${ }^{17}$.

De vierde plaat loopt over de jaren 1683-1711. De voorkant heeft zes namen. $\mathrm{Na}$ het derde merk staan de Ieperse stadsmerken en de dekanaatsletters kleine gothische $b$ en na het vierde staan tweemaal de stadsmerken en de dekanaatsletters van c tot o (afb. 5 en 6 ). Het laatste meesterteken is dit van Antoine De la Derrière. Hij was eerst zilversmid te Doornik en was zelfs deken van het gilde in 1674, 1682 en 1684. In 1685 leverde hij nog zilverwerk aan de stad ${ }^{18}$. In het hogervermeld inventaris ${ }^{19}$ komt een gedeelte voor van een aanvraag door $\mathrm{A}$. De la Derrière aan het Brugs zilversmedengilde. Het jaar is onbekend waarin hij ze deed. Daar zal hij niet aanvaard zijn geweest en zal dan te Ieper zijn aanvraag hernieuwd hebben, rond 1687. De achterzijde draagt de merken van elf meesters tussen 1697 en 1711 .

De vijfde plaat loopt over de periode 1714-44. Dan kwam Ieper aan Oostenrijk totdat het weerom door de franse troepen bezet werd. De eerste tien meestertekens komen reeds vóór op de vierde plaat. In 1714 zullen ze verplicht geweest zijn opnieuw hun merk te laten slaan. Van verscheidene is het een ander. Nog vijftien ander merken volgen tussen 1714 en 1744. Van enkele zilversmeden zijn er meerdere en verschillende merken geslagen.

De zesde en laatste plaat is deze van na de verordening

16. J. Casier, a.w., Pl. III, recto, 2e kol., 4e merk.

17. A. Schouteet, Inventaris van bet archief van bet voormalige ambacht van de goud- en zilversmeden te Brugge, in Handelingen Societe d'Emulation, 1952 blz. 64, nr. 41.

18. E.T. Soil de Moriamé, Orfèvrerie tournaisiennes du XVII et du XVIÍ Siècle à l'exposition de Tournai 1911 in Ann. Ac. Royale, 1912, p. 230.

19. A. Schouteet, a.w., blz. 63 , nr. $36 / 1$. 
van Maria Theresia. De zilversmeden moesten een nieuw meesterteken kiezen. Het is moeilijk uit te maken welke de voor- of achterkant is van de plaat. Wat echter opvalt is dat de eerste twaalf namen reeds op vroegere platen voorkwamen. Ze staan echter juist in de orde, waarin ze meester geworden zijn en de namen zijn allen in dezelfde letter in de plaat gegraveerd.

1. Joannes Baptist De Somer

Vrijmeester 1710

2. Pieter Joannes Balde

Vrijmeester 1710

3. Jan Paul Mullet

Vrijmeester 1714

4. Jan Baptist Kaes

Vrijmeester 1721

5. Caerle de Fourmestraux

Vrijmeester 1726

6. Augustinus Van der Steene

Vrijmeester 1726

7. Joannes Moreeuw

Vrijmeester 1731

8. G. Bourgoo

Vrijmeester 1734

9. Marinus Lenoir

Vrijmeester 1737

10. J.J. De Fourmestraux

Vrijmeester 1740

11. Constant Joseph Van Acker

Vrijmeester 1743

12. P. Joseph De Coene

Vrijmeester 1744

Nadien werden nog twee meestertekens bijgeslagen, dit van J(udocus) Van der Steene en van T. De Kerle. Hun namen zijn in ander schrift dan de twaalf voorgaande. Verder zijn geen ander meestertekens meer bijgeslagen geweest, hoewel er op kunstvoorwerpen merken van later datum voorkomen, waarvan de meester onbekend is.

De vijfde plaat van Gent geeft ook de zilversmeden weer met hun nieuw merk volgens het jaar dat ze meester geworden zijn. Het zijn de zilversmeden vanaf 1705 tot 14 mei $1749^{20}$.

In het Munthof te Brussel worden 120 « poincoenen » bewaard, waarmede de merken geslagen werden. Daaronder zijn stadsmerken o.m. de twee van Ieper, dekanaatsletters en meestertekens.

Volgende meestertekens van Ieperse zilversmeden zijn er bewaard :

20. J. Casier, a.w., Pl. V r ${ }^{\circ}$ 
Philip Joseph De Coene

Caerle de Fourmestraux

I.I. de Fourmestraux

Judocus Van de Steene

Marinus Lenoir

Pieter Joannes Balde

Jan Paul Mullet

Jan Baptist De Somer

Augustinus van de Steene

De merken van Augustinus Van de Steene en Philip Jos. De Coene zijn diegene die voorkomen op de 5e Pl. Al de andere zijn geslagen op de 6 e Plaat $r^{\circ}$ en $v^{\circ}$. Ze werden gedeeltelijk beschreven in Catalogue des Poinçons et Matrices du Musée de l'Hotel des Monnaies de Bruxelles door Alphonse de Witte in 1912. De meestertekens worden beschreven op blz. 134-36 doch er staan maar twee namen van Ieperse zilversmeden vermeld, nl. 48/Lenoir, en 60/J. De Somer. Daarbij worden nog 41 stempels bewaard waarvan het merk niet meer leesbaar is. Wellicht waren er nog ander meestertekens van Ieper bij. De vroegere Muntmeester Verlinde bezorgde een foto van de plaat waarop die 120 merken geslagen zijn.

De Brusselse zilversmid Sporenberg, kreeg eveneens de toelating om de merken op een kleine koperplaat van $9 \times 11$ te slaan en bezorgde er een foto van. Waar die plaat zich thans bevindt, is onbekend.

IV. Enkele families van Zilversmeden.

1) De Kien.

Een van de oudste families van Ieperse Zilversmeden is die van De Kien, soms ook genoemd de Hondt of Dhont. Verscheidene familieleden waren zilversmid. De oudste komen voor in de Ieperse stadsrekeningen. Het is echter onmogelijk te zeggen in welk verwantschap ze met elkaar stonden. a) De oudst bekende is Jan de Kiens of de Hondt ${ }^{21}$.

21. A. Merghelynk, Vademecum N 31 T X Comptes de la Ville d'Ypres. T 1 tot 10 ; 530 p. met Tafel : $4^{\circ}$ Deel 53 bis en $95 \mathrm{bis}$. 
b) Dan is er een Gheeraerd des Kins of d'Hondt ${ }^{22}$. Hij wordt ook in 1495 vermeld ${ }^{23}$; mogelijk is er een tweede Gheeraerd.

c) Roelant de Kien staat de eerste vermeld met zijn meesterteken op de eerste plaat, dit rond 1525. Dit eerste merk is een gotische hoofdletter $\mathrm{K}$ met boven links een $R$. Het zevende merk van dezelfde plaat is weerom een van Roelant de Kien, maar ditmaal is het een rechtslopende hond met $\mathrm{R}$ tussen kop en staart in een schildvormige omlijsting. Verder staat weerom een van Roelant, het is een gotische hoofdletter $\mathrm{K}$ in een vierkante omlijsting. Of het dezelfde persoon geldt, kon niet worden uitgemaakt. Het zijn in elk geval drie verschillende meestertekens.

d) Het derde merk van dezelfde plaat is dit van Joos de Kien. In een rechthoekige omlijsting staat I.K.

e) Nog een Roelant De Kien staat op de tweede plaat recto, nr. 3. Zijn merk is een zittende hond, de kop naar links gewend, in een schildvormige omlijsting. Rond dit schild staat de datum 1563 .

f) Op diezelfde plaat staat het meesterteken van Mattheus De Kien, die meester werd in 1581. Voor de «Bruiloftfeeste van Caerle Ryckewaert, dienare des woordts » leverde hij 2 Coppetassen ${ }^{24}$. Hij was gehuwd met Maria Thevelijn. Een tweede meesterteken staat nevens het eerste met datum 1608. Hij was schepen van Ieper in 1588-89. Dit is de laatste zilversmid De Kien, die voorkomt te Ieper.

Bij de Brugse zilversmeden waren rond diezelfde tijd :

a) Willem de Hondt overleden in 1531.

b) Joos de Hondt warandeerder van het gilde in 1545 .

c) Jan de Hondt vermeld in een proces van 1566, dan was hij 49 jaar.

22. A.W., $4^{\circ}$ Deel: 32 verschillende aanhalingen.

23. A. Vanden Peereboom: Ypriana, t. I, p. 167.

24. A. De Schrevel, Le protestantisme à Ypres et dans les environs, de 1578 à 1584. 


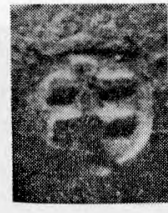

1

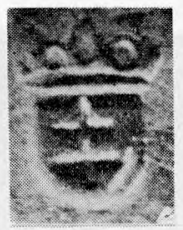

2

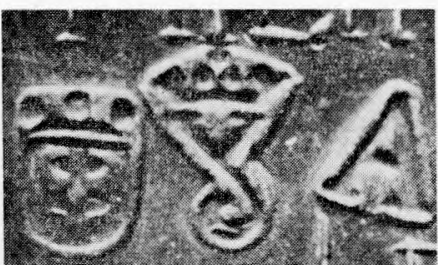

4

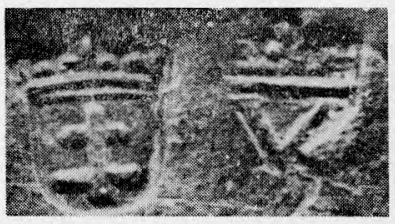

3

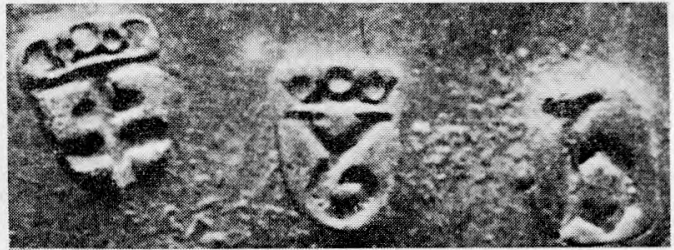

5

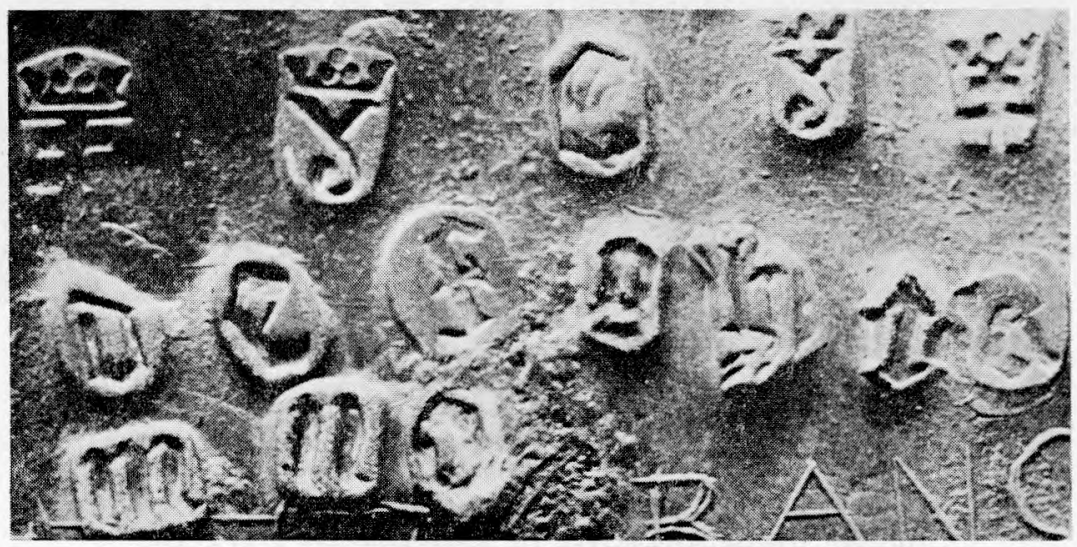

6

Afb. 1 : Iepers stadsmerk 1525 .

Afb. 2: Iepers stadsmerk begin 1600 .

Afb. 3: Ieperse stadsmerken 1612.

Afb. 4 : Ieperse stadsmerken en dekanaatsletter omstreeks 1664.

Afb. 5: Ieperse stadsmerken en dekanaatsletter 1684-85.

Afb. 6: Ieperse stadsmerken en dekanaatsletter

omstreeks 1684-1697.

De merken werden ca. driemaal vergroot. 

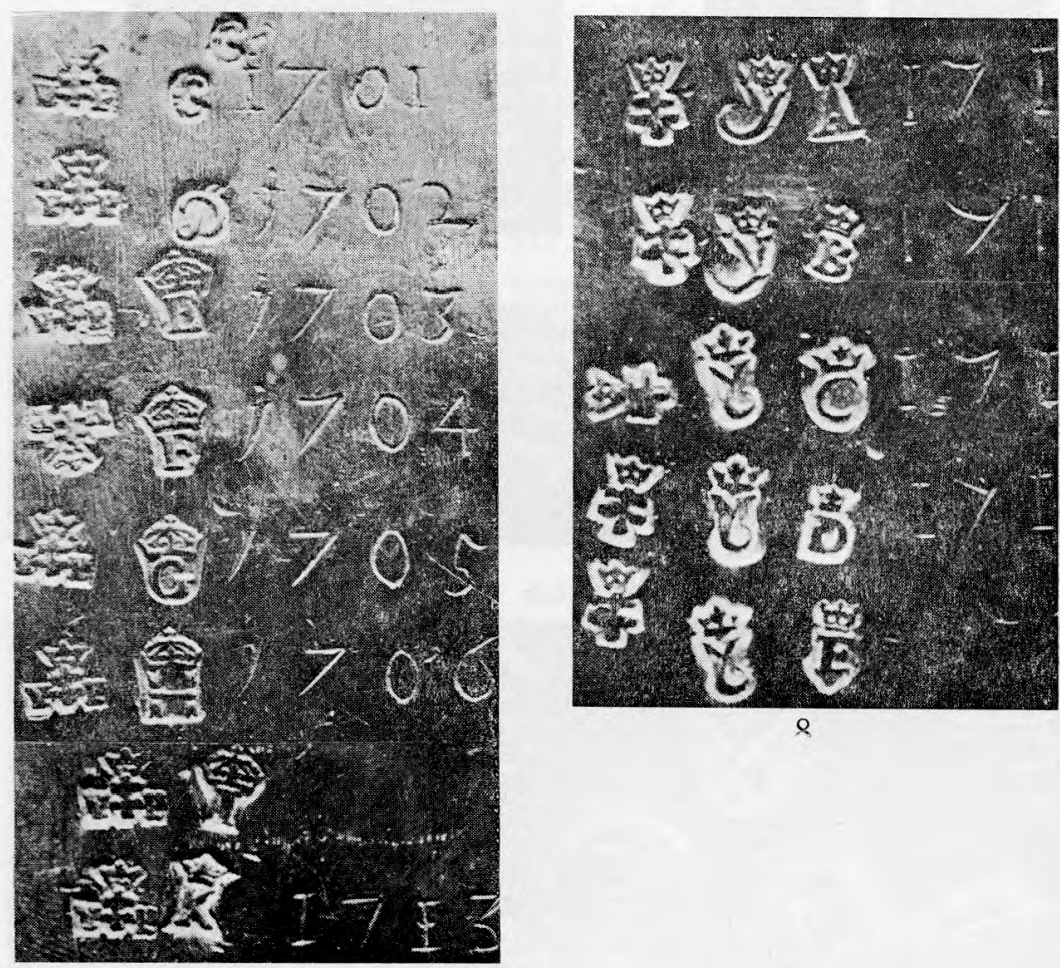

7

Afb. 7 : Ieperse stadsmerken en dekanaatsletters 1699-1713.

Afb. 8 : Ieperse stadsmerken en dekanaatsletters 1714-1744. 

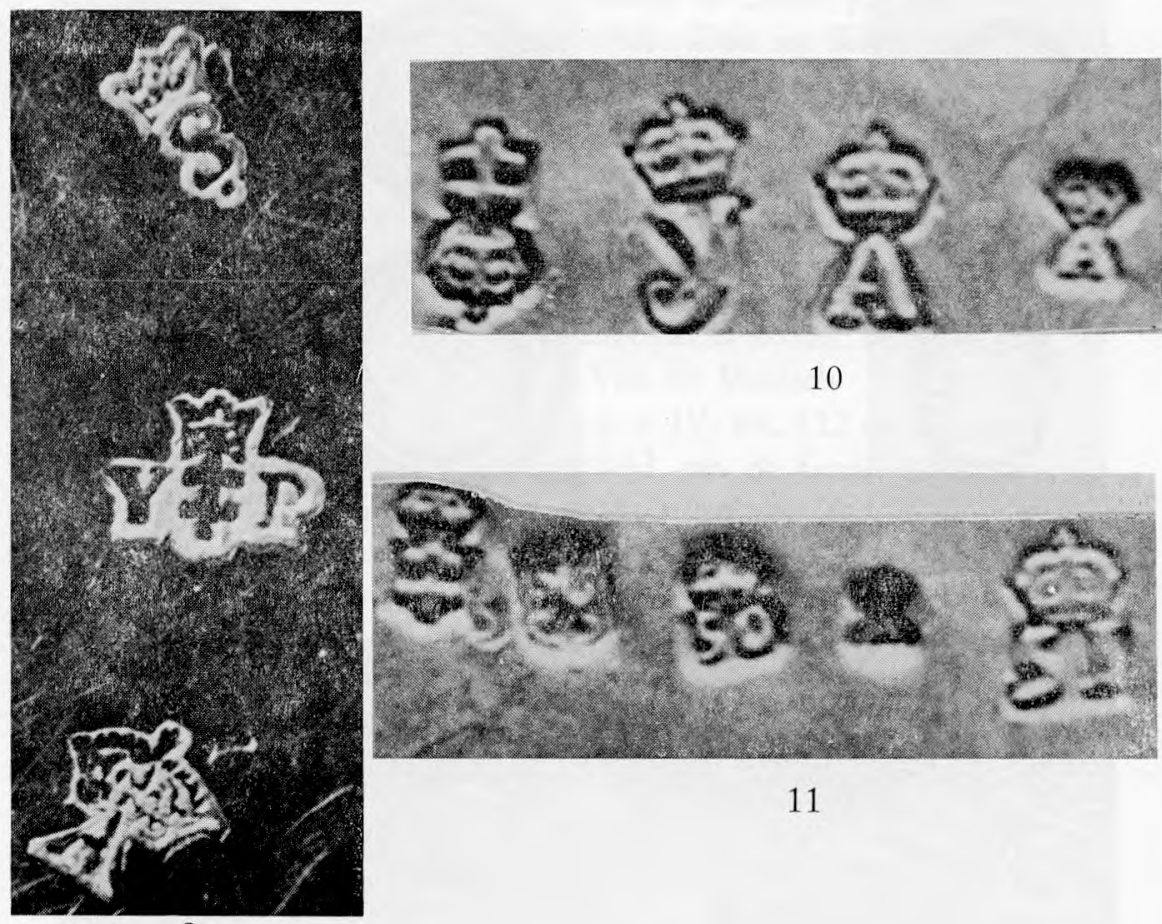

10

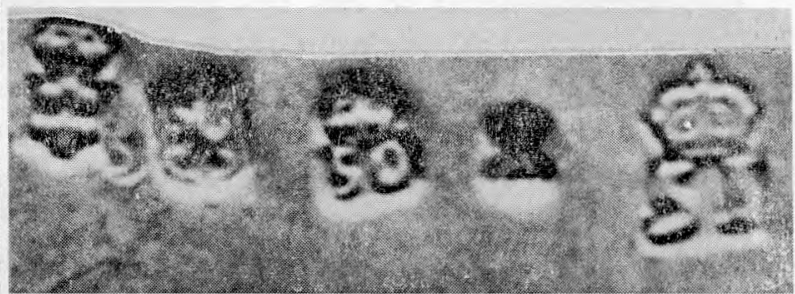

11

Afb. 9: Iepers stadsmerk, dekanaatsletter en meesterteken

(De Somer) 1745

Af. 10: Iepers stadsmerk, dekanaatsletter en meesterteken

(De Somer) 1745.

Afb. 11: Iepers stadsmerk en cijfers van 1750 tot 1793. 


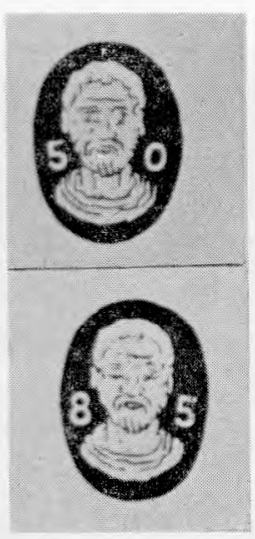

12

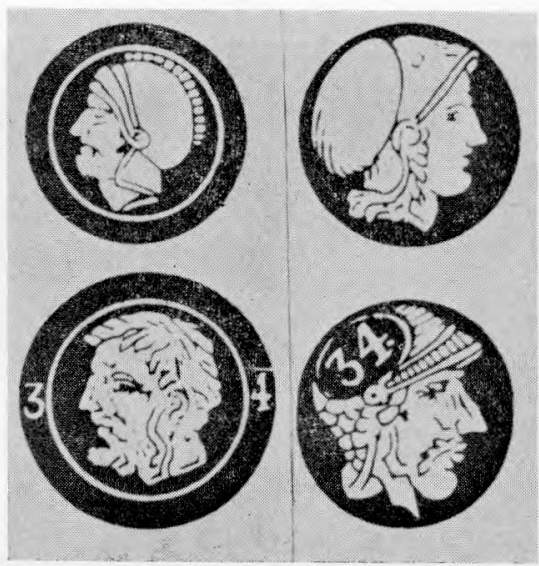

13

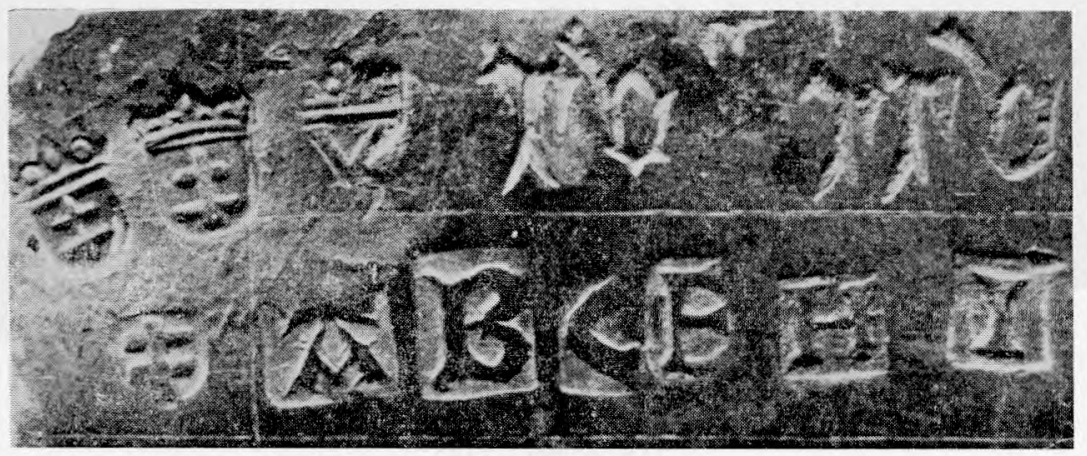

Afb. 12 : Merken gebruikt van 1798 tot 1809 .

Afb. 13: Merken gebruikt van 1809 tot 1814 .

Afb. 14 : Ieperse stadsmerken en dekanaatsletters 1525 .

Afb. 1 tot 11 en 14 : ACL. Brussel.

Afb. 12 en 13: Les poinçons en usage de 1797 à 1838, in Connaissance des Arts, Parijs, 1965, blz. 40. 
In Doornik was er een Simon le Quien joyelier 1491 en een Gilles le Kien 1510. Ook in Kortrijk komt een tak zilversmeden Dhondt vóór o.m. Charles de Hondt, waarvan het meesterteken voorkomt op de 6e Plaat van de zilversmeden nr. $5^{24 \mathrm{bis}}$. Zijn ze verwant met de zilversmeden de Kien de Hondt uit Ieper?

2) Van der Meersch.

Op de platen met de meestertekens komen verscheidene meesters voor van de familie Van der Meersch.

In « Tabettes des Flandres », t. IV, blz. 112 en volgende, wordt de afstamming behandeld van de familie Van der Meersch afkomstig uit Nieppe, waarvan maar één, nl. Olivier aangegeven is als zilversmid ${ }^{25}$.

Met behulp van deze genealogische gegevens zal getracht worden de zilversmeden, waarvan de merken op de platen voorkomen, te vereenzelvigen.

Charles III, of Caerle Van der Meersch, kleinzoon van Caerle (I) was poorter van Ieper. Hij is overleden in 1559. Hij huwde een 1e maal met Anna Van der Meersch, dochter van Jan en N. Dassonneville $(+1551)$ en vervolgens met Martina le Secq ${ }^{26}$. Het zal wel zijn meesterteken zijn dat voorkomt op de 1 e plaat $\mathrm{v}^{\circ}$, nr. 3 met zijn naam : Caerls van der Meersch. Uit het eerste huwelijk zijn drie kinderen bekend : Het is het eerste dat ons aanbelangt, $\mathrm{nl}$. Charles ${ }^{27}$.

Op de 2e plaat recto staat het merk van Caerle van der Meersch, meester-zilversmid geworden rond 1581 .

Uit het tweede huwelijk zijn vier kinderen bekend :

a) Allard ${ }^{28}$. Meer staat er over hem niet angetekend. Op de 2e plaat, recto, staat Alart van der Meersch, zonder merk, meester rond 1581 .

b) Olivier die in 1583 huwt met Maria Pankouke. Het zal

24bis. J. Casier, Poinçons des orfevres flamands.

25. Tablettes des Flandres, t. IV, blz. 112-121: Fragment généalogique d'une famille van der Meersch, originaire de Nieppe, par le Baron Albert Bonaert.

26. A.w., blz. 114.

27. A.w., blz. 114. 
ook zijn merk zijn op de 2 e plaat recto en hij werd meester in 1585 . Hij is de enige, die in hogervermelde genealogie als zilversmid wordt aangegeven. Hij stierf 25 januari $1601^{29}$. Hij had een zoon Olivier gedoopt St. Maartens Ieper 25 januari 1588. Hij huwde in 1606 met Joanna van de Steene en in 1611 met Anna Vleesch. Hij zal in 1606 meester-zilversmid geworden zijn want het merk van Olivier Van der Meersch staat geslagen op de 2e plaat, verso. Zijn vader, Olivier, was reeds in 1601 overleden.

De kinderen van Olivier, de jonge, die ook zilversmid werden zijn volgende :

a) Antoon rond 1629 gehuwd met Christine Passet ${ }^{30}$. Op de $3 e$ plaat, recto, staat het merk van Anthones van der mês, meester geworden in 1629 .

b) Guilliaume op 13 juli 1656 gehuwd met Joanna Quartiers, en overleden in 1678. In 1655 werd hij meesterzilversmid, volgens de $4 \mathrm{e}$ plaat, recto, waar hij vermeld staat als Guillames van Mesca. Hij had een zoon Guilliame die 18 jaar oud was bij de dood van zijn vader 30bis. Het is waarschijnlijk het meesterteken van deze Guilliames, dat geslagen is op de 4e plaat, recto, in 1683 en met een nieuw merk op de 5e plaat nr. 2 .

De enige, welke niet kon vereenzelvigd worden is Jan $V$ andermeersch, waarvan het meesterteken op de 1e plaat, verso, staat, nog vóór dit van Caerle; mogelijk is hij zijn broeder. In 1551 is een Jan Van der Meerscb voogd van een kind van Mahieu vander Meersch.

We kunnen dit schematisch zo voorstellen :

1. Caerle Van der Meersch +1559

(zilversmid (1e plaat $\mathrm{V}^{\circ}$ N. 3)

2. Caerle zilversmid rond 1581 , zoon van 1 . 2e Plaat $R^{\circ}$

3. Alart zilversmid rond 1581 , id. 2e Plaat $\mathrm{R}^{\circ}$

28. A.w., blz. 114 .

29. A.w., blz. 115.

30. A.w., blz. 117.

30bis. A.w., blz. 119. 
4. Olivier zilversmid 1585 , id. 2e Plaat $\mathrm{R}^{\circ}$

5. Olivier zoon van 4, zilversmid 1606. Geb. $1588+1650$. 2e Plaat $V^{\circ}$

6. Antoon, zilversmid 1629 , zoon van 5 . 3e Plaat $\mathrm{R}^{\circ}$

7. Guilliame zilversmid 1635 , zoon van 5 . $(+1678) 4$ e Plaat $\mathrm{R}^{\circ}$

8. Guilliame zilversmid 1683 , zoon van 7. 5e Plaat

3) Van de Steene.

Twee stammen Van de Steene moeten onderscheiden worden.

A) De oudste : zilversmeden van het Brugse gilde.

a) Joris Van de Steene, zoon van Christiaan was poorter van Ieper en zilversmid te Diksmuide. Hij komt niet voor op de platen der Ieperse zilversmeden, maar de Diksmuidse zilversmeden waren afhankelijk van het Brugse gilde. Hij was warandeerder van het Brugse gilde in 1648. Zijn eerste vrouw is gestorven 16 april $1661^{31}$. In 1664 hertrouwde hij met Petronelle Caura en koos «poorterie» te Ieper bij Pieter Vandesteene ${ }^{32}$. In de rand van het poortersboek staat : « 1672 al doot ».

6 oogst 1672 werd de huisvrouw van Joris Van de Steene te Diksmuide in de kerk begraven en 17 van de zelfde maand hij zelf ${ }^{33}$. Hij had twee zonen die zilversmid waren.

b) Pieter Ignatius eveneens poorter van Ieper en zilversmid te Diksmuide. Hij was gehuwd met Marie Françoise Voormersch in 1673 en hertrouwde in 1698 Marie-Barbara Van de Perre. Hij staat afgeschreven als poorter $1718^{34}$.

c) Ferdinand was poorter van Ieper en zilversmid te Roeselare, waar hij ook het poorterschap annam. Hij was gehuwd in 1673 met Petronelle Deryckere ${ }^{35}$. Bij de

31. J. Weale, Les églises du doyenné de Dixmude, p. 72 - 1660-61.

32. Haghepoorters van Ieper, t. IV, 2e Deel, $f^{\circ} 445$.

33. J. Weale, a.w., blz. 76.

34. Haghepoorters van Ieper, t. IV, 2e Deel, fo 445.

35. Haghepoorters van Ieper, t. IV, 2e Deel, fo 446. 
dood van zijn vrouw waren de voogden van zijn kinderen Pieter Ignatius Van de Steene zilversmid te Diksmuide en Joannes Deryckere zilversmid te Kortrijk ${ }^{36}$. B) De jongere generatie, zilversmeden van het Iepers gilde.

d) Augustinus van de Steene werd zilversmid te Ieper in 1726 , zijn merk staat geslagen op de 5 e plaat nr. 16 en zijn nieuw merk na 1749 op de 6 e plaat nr. 6. Van hem is in het Metropolitan Museum te New-York een theebus bewaard uit 1739 (nr. 48 : 187.879). Hij was gehuwd met Catharina Theresia Keingnaert. Drie zonen-zilversmid zijn van hem bekend.

e) Judocus - Augustinus geboren te Ieper en zilversmid te Roeselare, waar hij op 21-6-1768 poorter werd na ontpoorterd te zijn te Ieper. Hij huwde in dit jaar met Laurentia Joanna Spillebout, dochter van Niklaas en van Joanna Maria van Gobbelschroy, een voorname Roeselaarse familie ${ }^{37}$. Zijn merk komt voor op de laatste plaat nr. 13.

f) Frans Xaverius was zilversmid te Roeselare en woonde op de westzijde van de grote markt ${ }^{38}$.

g) Karel Van de Steene woonde te Diksmuide, waar hij zilversmid was. Hij leerde zijn ambacht bij Eugeen Mullet, zilversmid te Roeselare, en kocht er in 1777 zijn alaam af ${ }^{39}$. Hun meestertekens zijn niet bekend.

\section{4) De Somer.}

Jan-Baptist De Somer, zoon van Lieven en kleinzoon van Pieter werd te Ieper geboren rond $1679^{40}$. Hij werd er meester-zilversmid in 1710. Zijn meesterteken komt verscheidene malen voor : een eerste maal op de 4 e plaat verso nr. 10 met één merk, een ander maal op de 5 e plaat nr. 7

36. Stadsarchief Roeselare 934 Weezerie - (1681-90), nr. 239.

37. G. Marechal, De Poorters van Roeselare, blz. 61.

38. Stadsarchief Roeselare, boek 700, fo $224 \mathrm{v}^{\circ}$, en 701, f 247.

39. Stadsarchief Roeselare, boek 702, fo $281 \mathrm{v}^{\circ}$.

40 Tablettes des Flandres, deel V, biz. blz. 118 en volgende. 
met drie verschillende merken en een derde maal de eerste op de 6e plaat van 1750 met zijn nieuw merk. Hij huwde met Margriet De Langhe, die overleed 30 november 1724 en vervolgens met Marie-Isabelle De Meezemaker. Hij overleed 4 oktober 1750 . Uit zijn eerste huwelijk had hij 6 kinderen o.m. Marie-Margriet, die huwde met Filip Jozef De Coene, die zilversmid werd in 1744. Zijn merk staat het voorlaatste op de $5 \mathrm{e}$ plaat, het voorlaatste op de 6e plaat en derde laatste op dezelfde plaat verso. Uit zijn tweede huwelijk had hij nog drie kinderen waarvan Martinus-Robert, geboren 18 oktober 1730, zilversmid werd in 1752 en in 1754 huwde met Marie-Josephine Matthys. Zijn merk is niet bekend.

V. De «Subalterne steden van bet Ieperse zilversmedengilde.

Door Subalterne steden verstaat men steden, waar zilversmeden werkten, die ingeschreven waren in het Iepers zilversmedengilde.

De eerste stad is :

A) Roeselare met volgende zilversmeden :

1) Ferdinand van de Steene, zoon van Joris vestigde zich als zilversmid rond $1672^{41}$.

2) Baltbazar le Roy of de Roy werd meester-zilversmid in het Iepers gilde in 1710. Zijn meesterteken is geslagen op de $4 \mathrm{e}$ Plaat, verso nr. 8. In een akte van prokuratie van 12 mei 1733 lezen we dat hij zilversmid was te Roeselare.

3) Eugeen Hyacintbus Mullet zoon van Leonard, van Roeselare werd poorter te Ieper 10 oktober 1761 en was zilversmid te Roeselare. Hij was gehuwd met Marie-Caroline Picavet uit Veurne. Hij koos « poorterie » te Ieper bij zilversmid Verbrugghe ${ }^{42}$. Bij hem leerde Karel Vandesteene in 1777 zijn ambacht en hij verkocht hem zijn alaam. In 1786 woonde hij op de Oostkant van de

41. Zie Families 3/ Van de Steene A/e.

42. Haghepoorters Ieper IX. 
Noordstraat. Tot 1791 staat hij vermeld als poorter van Ieper - « Silversmit ».

4) Judocus Augustinus Vandesteene werd poorter te Roeselare 21 juni $1768^{43}$.

5) Frans-Xaverius Van de Steene was zilversmid te Roeselare en woonde aan de westzijde van de grote Markt ${ }^{44}$.

6) Karel Van de Steene eveneens reeds behandeld bij 3/ Familie Vandesteene $\mathrm{B} / \mathrm{g}$.

7) Paul-Joseph Delevoy werd geboren te Ieper en als poorter anvaard te Roeselare 26 februari $1777^{45}$. Hij was gehuwd met Maria Jacoba Nono.

8) Martinus Lenoir, zoon van Marinus zilversmid te Ieper, werd te Ieper ontpoorterd 24 mei 1787 en poorter van Roeselare 9 juli 1787. Hij was gehuwd met Anna Theresia Van de Walle ${ }^{46}$. Hij vestigde zich als zilversmid te Roeselare. Eerst kocht hij 2 huizen, die de noord-westhoek van de Mariastraat uitmaakten en daarna een huis op de grote Markt in 1784, dat hij zelf bewoonde ${ }^{47}$. Bij zijn ontpoortering had hij drie kinderen : Jozef, Maarten en Frans. Maarten huwde met Laurence-Amélie Rodenbach, dochter van Pieter en werd ook zilversmid.

In de hollandse tijd woonden er te Roeselare drie zilversmeden met de naam Lenoir op de Markt.

9) Constant Jozef Van Acker was goud- en zilversmid. Hij woonde in 1787 bij Judocus Van de Steene in de Noordstraat.

10) Ignaas Vermander, zoon van Jan Baptist was geboren te Roeselare. Hij was vrijmeester goud- en zilversmid geworden in het gilde te Ieper. Dit is bekend uit een getuigenis van 17 maart $1794^{48}$.

B) Poperinge.

Weinig zilversmeden uit Poperinge zijn bekend. Einde

43. Zie Families 3/ Vandesteene B/e.

44. Zie Families 3/ Vandesteene B/f.

45. G. Marichal, a.w., blz. 21-22.

46. G. Marichal, a.w., blz. 41 Haghepoorters Ieper, deel IX.

47. Stadsarchief Roeselare, boek 704/082.

48. Stadsarchief, Roeselare, boek $705, \mathrm{f}^{\circ} 345 \mathrm{v}^{0}$. 
augustus 1700 waren moeilijkheden ontstaan omdat zilverwerk van lager gehalte gemaakt werd bij verscheidene zilversmeden. De eed van Rijsel samen met die van Ieper moesten er zich naartoe begeven. $\mathrm{Zij}$ moesten zich terugtrekken en de aangeslagen voorwerpen teruggeven. Dit op bevel van de magistraat ${ }^{49}$.

De enige met bekendheid is Henri Boeys. Hij is geboren te Poperinge (St. Bertinus) 10 augustus 1754 als negende kind van Joannes en Elisabeth Tanghe. Zijn vader stond bekend, zoals de overlijdensakte meldt, als « famosus faber aerarius », koperslager. Hij huwde 2 december 1783 met Maria Joanna Platteau uit Roeselare. Hij was reeds meester-zilversmid vóór 1781, want er is reeds werk van hem bekend uit dit jaar. In en rond Poperinge wordt er edelsmeedwerk van hem angetroffen. Hij overleed te Poperinge 27 januari 1831. Hij had maar één zoon Jan-Henri Boeys te Poperinge (St. Bertinus) geboren 6 juli $1785^{50}$.

In Winoksbergen wordt nog een plaat met meestermerken bewaard uit het begin van de $19 \mathrm{e}$ eeuw. Daarop komt het merk voor van J.H. Boeys. In de St. Maartenskerk te Winoksbergen was een reliekschrijn van de $\mathrm{H}$. Winok, gemaakt in 1823 door Boeys, vader en zoon ${ }^{51}$. Zijn zuster Angèle was in 1765 gehuwd met Frans De Puydt.

Haar zoon Jan-Frans De Puydt, geboren te Poperinge (St. Bertinus) 3 april 1767 en gehuwd met Bénédicta Bonte, was eveneens zilversmid te Poperinge. Zijn meesterteken is niet bekend en geen werk kon hem worden toegeschreven.

Dit zijn de enige tot nu toe bekende zilversmeden te Poperinge.

De volgende stad mag niet als echte Subalterne Stad beschouwd worden, maar er zijn Ieperse zilversmeden, die er hun ambacht uitgeoefend hebben.

49. J. Descamps, Histoire de la Corporation des Orfèvres de Lille (1926), blz. 104.

50. Parochieregisters - Poperinge, medegedeeld door $\mathrm{Hr}$ Guido Boerave, waarvoor beste dank.

51. Histoire de Bergues, t. II, p. 179. 
Het is het geval voor Veurne. De bekende zilversmeden te Veurne gevestigd, waren zilversmid in het Brugse gilde. De enige bekende uitzondering is Pieter Lebeau, de oude, meester geworden in $1683^{52}$. Van 1700 tot 1715 werkte hij bijna ieder jaar voor het kapittel van St.-Walburgis te Veurne. In de kerkrekening van 1701 uit Lombardsijde staat dat hij «Silversmit was tot Veurne».

Drie andere zilversmeden, die te leper hun ambacht leerden, deden de aanvraag om opgenomen te worden in het Brugse gilde en dit werd hun toegestaan.

Het waren : Jan-Baptist Nonckle Meester 27 febr. 1722; Jan François D'Hennin Meester 1 maart 1722; en Franciscus Schoonaert Meester 17 dec. $1754^{53}$. Ze waren te Veurne gevestigd*.

C. DENORME.

52. 4 Plaat, verso, nr. 1.

53. Ann. Em. 1952: H. Schouteet, Inventaris van bet archief (reeds aangehaald). Nr. 19 Dossier tot aanneming tot vrijmeester goudsmid te Brugge van Frans Schoonaert.

* Een woord van dank aan Weleerw. Heer A. Deschrevel en Heer O. Mus voor hun inlichtingen. 